\title{
Effect of Plank Exercise Combined with Breathing and Arm Exercises on Abdominal Muscle Thickness
}

\author{
Jae-Cheol Park', Yong-Nam Kim² \\ 'Department of Physical Therapy, Chunnam Techno University; ${ }^{2}$ Professor, Department of Physical Therapy, Nambu University, Gwangju, Korea
}

Purpose: This study examined the effects of plank exercise combined with breathing and arm exercises on the external oblique, internal oblique, and transverse abdominal muscle thickness.

Methods: Thirty healthy adults consisting of 12 males and 18 females from $\mathrm{K}$ area were divided into a plank exercise combined with breathing and arm exercises group $(n=15)$ and a plank exercise only group $(n=15)$. The changes in muscle thickness before the exercise and four and eight weeks after the exercise were analyzed using a two-way repeated analysis of variance (ANOVA). The significance level was set to $\alpha=0.05$. Post-hoc t-tests were conducted to detect the interactions between the time and groups, and the significance level was set to $\alpha=0.01$.

Results: According to the experimental results, the external oblique abdominal muscle showed significant differences over time $(p<0.05)$. The internal oblique abdominal muscle also showed significant differences over time and in the interactions between the time and groups $(p<0.05)$. The transverse abdominal muscle showed significant differences over time, in the interactions between time and groups, and in the changes between the groups $(p<0.05)$.

Conclusion: The results indicated that plank exercise combined with breathing and arm movement exercises led to increases in the abdominal muscle thickness. These types of exercises may be useful in lumbar stabilization rehabilitation treatment.

Keywords: Respiration, Muscle thickness, Plank exercise, Arm Exercises

\section{서 론}

몸통 앞쪽을 구성하는 복부 근육들은 몸통의 움직임과 척추 분절의 안정성에 관여하고 ${ }^{1}$ 복부 근육의 약화는 척추 불안정성을 유발하여 각종 질환을 발생시키므로 임상에서는 복부 근육 강화를 위해 허리 안정화 운동을 자주 이용한다. 허리 안정화 운동은 미세손상이나 통 증으로부터 척추 주변 구조물들을 보호하고 기능 장애를 개선하기 위한 방법으로 ${ }^{2}$ 기구 또는 도구를 이용한 허리 안정화 운동, ${ }^{3,4}$ 교각 운동(bridge exercise), ${ }^{5}$ 플랭크 운동(plank exercise) ${ }^{6}$ 등이 자주 이용되 고 있다. 여러 안정화 운동 중 플랭크 운동은 복부 근육의 근력과 지 구력을 증진하고 척추의 안정성을 증가시키기 위해 고안된 체중 운 동으로 ${ }^{7}$ 복부 근육의 활성도를 증가시키는 대표적인 안정화 운동이 다. ${ }^{8}$ 하지만 정적인 반복 동작으로 인하여 학습된 운동 조절능력 상 승은 ${ }^{9}$ 운동에 대한 효율을 감소시키기 때문에 전통적인 플랭크 운동 방법과 함께 적용 가능하며 운동 효과를 극대화하려는 방법들이 필
요하며 함께 적용 가능한 방법으로 호흡 기법을 이용한 방법과 ${ }^{10}$ 팔 이나 ${ }^{11}$ 다리를 이용한 방법 등이 보고되고 있다. 호흡 기법이나 팔의 움직임을 이용한 복부 강화 운동은 근 · 뼈대계에 질환에 효과적이 며 ${ }^{10}$ 여러 원인에 의해 안정화 운동을 적용하지 못하는 특수성을 가 진 집단에 운동 방법이 간단하고 쉽게 따라 할 수 있어 효과적으로 적용하기 쉽다.

호흡은 호흡으로 인해 발생하는 기도 저항과 복부 벽에 의해 발생 하는 부하를 이겨내기 위한 복부 근육들의 활동이 필요하다. ${ }^{12}$ 복부 근육은 노력성 날숨에 중요한 역할을 함과 동시에 ${ }^{13}$ 자세 안정화에 관여하고 있다. ${ }^{14}$ 이러한 복부 근육 약화는 호흡 문제를 발생시킬 수 있고 몸통의 불안정성을 유발하기 때문에 복부 근육 강화의 필요성 이 대두되고 있다. Ishida와 Watanabe ${ }^{15}$ 은 날숨을 하는 동안 배가로근 근막의 두께가 증가한다고 하였고, Lee ${ }^{16}$ 은 호흡운동이 몸통 근육들 을 활성화해 신체 안정성을 높이며 안정화 근육의 강화를 유도한다 고 하였으며 호흡을 이용한 모든 운동은 배속빗근과 배가로근, 뭇갈
Received Jul 1, 2019 Revised Aug 2, 2019

Accepted Aug 6, 2019

Corresponding author Yong-Nam Kim

E-mail kyn0231@nambu.ac.kr
Copylight (C)2019 The Korean Society of Physical Therapy

This is an Open Access article distribute under the terms of the Creative Commons Attribution Non-commercial License (Http:// creativecommons.org/license/by-nc/4.o.) which permits unrestricted non-commercial use, distribution, and reproduction in any medium, provided the original work is properly cited. 
래근의 근활성도를 증가시킨다고 보고하였다. ${ }^{17}$ 더불어 팔을 이용한 방법도 호흡과 더불어 안정화운동에 적용할 수 있다. Lee 드이은 팔의 움직임은 복부 근육의 활성화에 효과적으로 작용한다고 하였으며, 팔을 들어 올릴 때 배속빗근의 근활성도가 증가한다고 하였다. ${ }^{18}$ 팔 의 움직임은 아니지만 Mok 등 19 은 다리의 벌림 운동 또한 복부 근육 활성화를 시킨다고 하였고, Park 등 ${ }^{20}$ 은 교각 운동 도중에 엉덩관절 모음을 동반한 운동이 배바깥빗근의 근활성도가 증가하여 팔과 다 리의 움직임이 복부 근육의 활성화를 시킨다는 것을 알 수가 있다.

이처럼 선행 연구들에 의해 호흡과 팔과 다리를 이용한 운동 효과 는 많이 보고되고 있지만 대부분 개별적으로 호흡 기법이나 팔과 다 리의 움직임을 적용하여 호흡 기능, 또는 몸통 근육의 활성화에 대한 논의는 많이 있었으나 물리치료 분야에서 자주 이용되는 플랭크 운 동과 호흡, 팔의 움직임을 병행한 훈련을 장기간 중재 후 배바깥빗근, 배속빗근, 배가로근의 두께에 미치는 영향에 관한 연구가 부족한 실 정이다. 그러므로 본 연구는 호흡과 팔의 움직임을 적용하여 플랭크 운동을 시행한 후 초음파로 형태학적 변화인 복부 근두께 변화를 알 아보고자 하며 안정화 운동의 기초 자료와 임상에서 복부 근육 강화 운동 치료로서 가능성을 제시하려고 한다.

\section{연구 방법}

\section{1. 연구대상}

본 연구는 N대학에 재학 중인 건강한 20 대 남자 12 명, 여성 18 명, 총 30 명을 대상으로 시기별로 나누어 8 주간 호흡과 팔의 움직임을 병행 한 플랭크 운동군(plank exercise group with respiration and arm movements, PERA), 15명 플랭크 운동군(plank exercise group, PE) 15명으로 나누어 집단에 대한 정보를 대상자에게 알리지 않고 단일맹검법(single-blind test)으로 대상자를 무작위로 군을 분류하여 운동 시간대를 달리하여 실험을 하였다. 실험 전 근. 뼈대계와 정형외과적 질환이 없 는 자, 정기적으로 운동을 하지 않은 자로 연구에 대한 목적 및 운동 방법 등을 설명하고 자발적인 연구 참여를 희망하고 연구 동의서를

Table 1. General characteristics of subjects

\begin{tabular}{lccc}
\hline & PERA $(\mathrm{n}=15)$ & PE $(\mathrm{n}=15)$ & $\mathrm{p}$ \\
\hline Age (year) & $20.3 \pm 1.11$ & $20.5 \pm 1.18$ & 0.273 \\
Height $(\mathrm{cm})$ & $167.1 \pm 8.39$ & $167.4 \pm 9.99$ & 0.451 \\
Weight $(\mathrm{kg})$ & $60.8 \pm 9.59$ & $60.5 \pm 13.22$ & 0.209 \\
BMI $\left(\mathrm{kg} / \mathrm{m}^{2}\right)$ & $21.6 \pm 2.02$ & $21.2 \pm 2.14$ & 0.611 \\
Gender & & & \\
Male & 6 & 6 & \\
Female & 9 & 9 & \\
\hline
\end{tabular}

PERA: plank exercise group with respiration and arm movements, PE: plank exercise group, BMl: body mass index.
작성한 자로 선정하여 연구를 시행하였고 대상자의 일반적 특성은 다음과 같다(Table 1).

\section{2. 실험방법}

\section{1) 연구 절차 및 운동 방법}

PERA와 PE에서 이용된 플랭크 운동 방법은 어깨 관절과 팔꿉 관절 을 90 도 굽힘을 하여 아래팔로 지지면을 지지하였고 시선은 바닥을 향하였으며 골반은 중립 위치에서 발은 어깨너비만큼 벌린 상태에서 운동을 실시 하였고 PERA는 실험 전에 정확한 호흡 방법 숙지를 위 해 누운 자세에서 들숨은 가로막 호흡을 연습하였다. 연구자 손을 대 상자 갈비연골 7번부터 12 번 위치에 올려놓고 호흡에 방해가 되지 않 을 정도에 저항을 주면서 깊은 들숨을 유도하였으며 날숨은 복부를 수축하면서 입술 오므리기 호흡을 이용하여 10 분간 연습 운동을 하 였다. ${ }^{2}$ 팔과 호흡을 이용한 플랭크 운동을 위해 운동 프로그램을 재 구성하였고 운동을 할 때 정확한 방법을 이용하기 위해 2 주 차이를 두면서 점진적으로 운동 강도를 조절하였다. 1 주에서 2 주까지는 호 흡을 이용한 플랭크 운동을 하였고 3 주와 4 주 차까지는 호흡과 팔을 약 45도 벌림을 이용한 운동을 하였으며 5주 후부터 호흡과 팔을 90 도 벌림 운동을 하였다. 들숨을 시작하면서 팔의 움직임을 시작하였 고 날숨 마지막 부분에서 일반적 플랭크 자세로 되돌아왔으며 좌. 우 측 팔을 번갈아 가며 벌림 운동을 실시 하였다. $\mathrm{PE}$ 는 호흡과 팔의 움 직임이 없는 일반적 플랭크 운동을 하였고 두 그룹은 총 30 분간 운동 을 적용하였으며 준비운동으로 가벼운 걷기 운동 5 분을 적용하였고 본 운동 20 분, 마무리 스트레칭 운동 5 분으로 구성하였다. 본 운동은 들숨 6 초 날숨 6 초를 유지하면서 1 분간 플랭크 운동을 하였고 1 분 사 이에 30 초간 휴식 시간이 주어졌다. 반복 운동으로 인해 피로도의 증 가를 고려하여 운동 중간에 큰소리로 독려 하였으며 총 20 분간 주 3 회 8 주간 실시하였다.

\section{2) 측정도구 및 방법}

복부 근두께 측정은 초음파 영상 장치를(V2u Health Care, Singapore) 이용하였고, 변환기는 $3.5 \mathrm{MHz}$ 선형탐촉자(linear transducer)를 주파 수 변조 범위는 8-10 MHz를 이용하였다. 배바깥빗근, 배속빗근, 배가 로근의 측정자세로 대상자는 바로 누운 상태에서 무릎관절 $45^{\circ}$ 굽힘 을 한 후 배꼽에서 몸통 바깥쪽으로 약 $13 \mathrm{~cm}$ 떨어진 지점과 겨드랑 이 부위와 위앞엉덩빼가시(ASIS)를 직선으로 그어 두 지점이 만나는 곳에서 초음파 화면상 배바깥빗근이 왼쪽에 있게 하여 초음파 화면 정 가운데에서 근두께를 획득하였다. 호흡 주기가 근두께에 영향을 미칠 수 있어 날숨 마지막 단계에서 호흡을 멈추고 측정하였으며, ${ }^{21}$ 충분한 초음파 겔을 이용하여 피부에 발라 초음파 이미지를 획득하 였고 측정 부위를 오류를 감소하기 위해 수술용 펜으로 지점을 표시 
Table 2. Comparison of trunk muscle thickness

$(\mathrm{mm})$

\begin{tabular}{|c|c|c|c|c|c|c|c|}
\hline & & Pre & 4 weeks & 8 weeks & Source & $\mathrm{F}$ & $p$ \\
\hline \multirow[t]{3}{*}{ EO } & PERA & $4.65 \pm 0.86$ & $4.86 \pm 0.87$ & $5.36 \pm 0.91$ & Time & $37.950^{* *}$ & $0.000^{* *}$ \\
\hline & PE & $4.65 \pm 0.84$ & $4.76 \pm 0.84$ & $5.05 \pm 0.69$ & TimeX Group & 3.141 & 0.059 \\
\hline & & & & & Group & 0.217 & 0.645 \\
\hline \multirow[t]{3}{*}{10} & PERA & $6.84 \pm 1.34$ & $7.46 \pm 1.22$ & $8.44 \pm 1.13$ & Time & $58.944^{* *}$ & $0.000^{* *}$ \\
\hline & PE & $6.54 \pm 1.58$ & $6.77 \pm 1.70$ & $7.00 \pm 1.65$ & TimeX Group & $16.332^{* *}$ & $0.000^{* *}$ \\
\hline & & & & & Group & 2.396 & 0.133 \\
\hline \multirow[t]{3}{*}{$\operatorname{Tr} A$} & PERA & $3.26 \pm 0.54$ & $3.77 \pm 0.59$ & $4.38 \pm 0.72$ & Time & $89.907^{* *}$ & $0.000^{* *}$ \\
\hline & PE & $3.08 \pm 0.59$ & $3.34 \pm 0.71$ & $3.66 \pm 0.50$ & TimeX Group & $9.354^{* *}$ & $0.000^{* *}$ \\
\hline & & & & & Group & $4.339^{*}$ & $0.047^{*}$ \\
\hline
\end{tabular}

EO: external oblique, IO: internal oblique, TrA: transverse abdominis, PERA: plank exercise group with respiration and arm movements, PE: plank exercise group, Mean $\pm S D,{ }^{*} p<0.05,{ }^{* *} p<0.001$.

하고 변환기를 피부와직각으로 유지하여 좌측 근두께를 획득하였다. 몸통의 해부학적 지식 및 초음파 검사기에 숙달된 물리치료사 1 인을 선정하여 총 3 회 반복 측정을 하여 평균값을 근두께로 이용하였다.

\section{3. 분석방법}

본 연구에서 획득한 자료는 통계 프로그램 SPSS for window ver 19.0를 이용하였다. 대상자의 일반적 특성의 정규분포 여부를 위해 단일표 본 Shapiro-wilk 검정을 하였고 정규분포가 인정되어 두 그룹의 운동 전, 4 주 후, 8 주 후의 근두께 변화를 알아보기 위해 2 요인 반복측정 분산분석(Two-way repeated ANOVA)을 이용하였고 $\alpha=0.05$ 로 하였 다. 시기와 군간 상호작용이 있는 경우 집단 내 차이를 확인하기 대응 표본 t-검정(paired t-test)를 집단 간 차이를 확인하기 위해 독립표본 t검정(independent t-test) 사후분석으로 실시하였고 ${ }^{22} \mathrm{I}$ 종 오류를 위해 $\alpha=0.01$ 로 하였다.

\section{결 과}

\section{1. 배바깥빗근 두께 변화}

각 군의 배바깥빗근 두께 변화에 대한 결과 시기별에서 유의한 차이 가 있었고 $(\mathrm{p}<0.05)$, 시기와 군간 상호작용, 집단간 변화에서 유의한 차이가 없었다( $\mathrm{p}>0.05)$ (Table 2).

\section{2. 배속빗근 두께 변화}

각 군의 배속빗근 두께 변화에 대한 결과 시기별, 시기와 군 간 상호 작용에서 유의한 차이가 있었고 $(\mathrm{p}<0.05)$, 집단간 변화에서는 유의한 차이가 없었다( $\mathrm{p}>0.05)$ (Table 2). 사후분석 결과 8주 후에서 PERA와 $\mathrm{PE}$ 의 두 집단에서 유의한 차이가 있었다 $(\mathrm{p}<0.01)(T a b l e ~ 3)$.
Table 3. Post-hoc according to interactions of time and groups in PERA and $P E$

\begin{tabular}{llccll}
\hline & & After 4weeks $^{\mathrm{a}}$ & ${\text { After } 8 \text { weeks }^{\mathrm{b}}} \mathrm{t}$ & $\mathrm{p}$ \\
\hline IO & PERA & $0.62 \pm 0.26$ & $1.60 \pm 0.59$ & $7.384^{* *}$ & $0.000^{\text {** }}$ \\
& PE & $0.23 \pm 0.25$ & $0.46 \pm 0.49$ & 2.22 & 0.043 \\
& $\mathrm{t}$ & 1.280 & $2.784^{+}$ & & \\
& $\mathrm{p}$ & 0.211 & $0.010^{+}$ & & \\
TrA & PERA & $0.50 \pm 0.20$ & $1.12 \pm 0.38$ & $6.167^{* *}$ & $0.000^{* *}$ \\
& PE & $0.25 \pm 0.33$ & $0.57 \pm 0.41$ & $3.971^{*}$ & $0.001^{*}$ \\
& t & 1.793 & $3.196^{+}$ & & \\
& p & 0.084 & $0.003^{+}$ & & \\
\hline
\end{tabular}

IO: internal oblique, TrA: transverse abdominis, PERA: plank exercise group with respiration and arm movements, PE: plank exercise group, 'Difference between pre and 4 weeks, ${ }^{b}$ Difference between pre and 8 weeks, Mean $\pm S D,{ }^{*} p<0.05$, ${ }^{* *} p<0.001$, ${ }^{+}$Post-hoc t-test $p<0.01$.

\section{3. 배가로근 두께 변화}

각 군의 배가로근 두께 변화에 대한 결과 시기별, 시기와 군 간 상호작 용, 집단간 변화에서 유의한 차이가 있었다 $(\mathrm{p}<0.05)$ (Table 2). 사후분 석 결과 8 주 후에서 PERA과 $\mathrm{PE}$ 의 두 집단에서 유의한 차이가 있었다 $(\mathrm{p}<0.01)$ (Table 3).

\section{고 찰}

호흡작용은 복부 근육에 수축과 이완에 영향을 미치며 호흡을 이용 한 훈련은 허리 통증에 효과적이다. ${ }^{23}$ 또한, 팔의 움직임은 복부 근육 의 활동을 유발하여 몸통의 안정성에 도움이 되므로 ${ }^{24}$ 호흡과 팔의 움직임을 이용한 플랭크 운동이 복부 근육 강화에 효과적이라 생각 되어 실험을 설계하였고 복부 근두께에 미치는 영향을 알아보고자 15 명씩 두 그룹으로 운동 전, 4 주 후, 8 주 후로 시기를 나누어 복부 근 육 두께의 변화를 초음파 영상 장치를 이용하여 측정하였다. 본 연구 에서 이용된 초음파 영상 장치는 신뢰도 연구에서 신뢰도가 높은 장 
비로 알려져 있고 심부 조직의 구조 및 근두께 측정과 확인하는 데 있 어, ${ }^{25}$ 필수적인 장비이며 임상에서 자주 이용되고 있다. ${ }^{26}$

본 연구 결과를 보면 배속빗근은 시기별에서만 유의한 차이가 있 었고, 배속빗근은 시기별, 시기와 군간 상호작용에서 유의한 차이가 있었으며, 배가로근은 시기별, 시기와 군간 상호작용, 집단간 변화에 서 유의한 차이가 있었다. 배속빗근에서 상호작용이 발생하였지만, 집단 변화에서 유의하지 않은 결과는 높은 상호작용이 주 효과를 가 리는 가면 효과(masking effect)로 생각된다. ${ }^{27}$

호흡을 이용한 선행연구를 살펴보면 복부 수축을 유도하는 복부 드로잉-인(abdominal drawing-in) 기법과 자주 이용되고 있고 최대 날 숨과 복부 드로잉-인 방법을 적용은 배바깥빗근의 근활성도와 배속 빗근, 배가로근의 근두께에 영향을 미치는 것을 확인하였다. ${ }^{28} \mathrm{Park}$ 는 29 복부 날숨 전략과 복부 드로잉-인 운동이 배가로근의 두께는 증가 시킨다고 하였다. 더불어 플랭크와 팔의 움직임을 이용한 선행연구로 는 Cortell-Tormo 등 30 은 15 명의 참가자로 골반 기울임과 어깨뼈 모음 을 하면서 플랭크 운동을 시행하면 배바깥빗근과 배속빗근의 근활 성도가 증가하는 것을 확인하였으며, 팔에 스위스 볼을 적용한 플랭 크 운동은 배바깥빗근과 배가로근의 활성도가 증가에 효과적이라고 보고하였다. 선행연구에서 이용한 복부 드로잉-인 방법은 심부 근 육인 배속빗근과 배가로근을 수축 시켜 복부 내압을 증가시키는 운 동 방법으로 호흡을 함께 적용하면 배바깥빗근의 활동이 증가한다 고 하여 배바깥빗근에서 본 연구와 대조를 이루었다. 이러한 차이는 측정 장비, 운동 형태와 기간 차이로 해석된다. 선행연구는 배속빗근 의 근활성도 변화를 확인한 연구이고 본 연구는 형태학적 변화인 근 두께 변화를 확인한 이유로 배바깥빗근에서 차이가 없었던 것으로 생각된다. 근육 두께 증가를 위해서는 저강도 운동의 경우 8 주 이상 의 기간이 필요로 한다. ${ }^{32}$ 본 연구에서 8 주의 기간을 적용하였지만 호 흡과 팔의 움직임을 이용하여 배바깥빗근 두께 증가를 위해서는 기 간이 부족했다고 생각된다. 플랭크 운동 관련 연구에서도 배바깥빗 근에서 차이가 있었다. 다양한 플랭크 운동 방법과 자세에 따라 복부 근육의 활동은 다르게 발생하고 ${ }^{33}$ 운동 도중 팔과 다리 골반의 움직 임은 복부에 다른 영향을 미친다. 선행연구의 골반 뒤 기울임(posterior tilt) 움직임은 배곧은근과 배바깥빗근이 작용하여 가능하다. 하지 만 본 연구는 골반 중립 위치에서 호흡과 팔의 움직임을 이용한 운동 을 하여 배바깥빗근의 활성이 적었던 것으로 생각된다. 또한 불안정 면에서 플랭크 운동은 복부 근육 중 배바깥빗근의 활동을 유도한 다. ${ }^{19}$ 안정면에서 운동과 비교하여 스위스볼이 지지면이 더 불안정하 고 도구의 크기 또한 커서 신체의 중심도 높아지므로 불안정성을 감 소시키기 위해 상대적으로 배바깥빗근이 활성화된 결과로 생각된다.

본 연구에서 시기와 군간 상호작용이 있는 경우 사후분석을 그룹 간과 그룹내로 나누어 분석하였다. 배바깥빗근에 상호작용이 없어
사후분석을 하지 않았지만 배바깥빗근 변화량을 보면 PERA는 4 주 후에 $0.21 \mathrm{~mm}, 8$ 주 후에는 $0.5 \mathrm{~mm}$ 의 증가를 했고 배속빗근은 4 주 후 에 $0.62 \mathrm{~mm}, 8$ 주 후에 $1.60 \mathrm{~mm}$ 의 증가를 했으며, 배가로근은 4 주 후에 $0.50 \mathrm{~mm}, 8$ 주 후에 $1.12 \mathrm{~mm}$ 의 증가를 했다. 또한, PE보다 PERA의 배 속빗근은 4주 후에 $0.39 \mathrm{~mm}$ 8주 후는 $1.14 \mathrm{~mm}$ 증가를 했고 배가로근 은 4 주 후에 $0.25 \mathrm{~mm}$ 와 8 주 후에 $0.54 \mathrm{~mm}$ 의 증가를 했다. 배속빗근과 배가로근의 8 주 후 변화량은 호흡으로 인해 심부 근육의 수축 유도 와 추가된 팔의 움직임으로 인하여 몸통에 외부 동요로 작용하고 그 로 인한 몸통 불안정성과 몸통의 가쪽굽힘이 발생하여 ${ }^{36}$ 골반과 몸 통 불안정성을 확보하고자 호흡과 몸통 안정화에 관여하는 배속빗 근과 배가로근의 활동이 상대적으로 크게 작용하여 두께 변화량이 발생한 것으로 생각된다. 호흡과 병행한 플랭크 운동은 아니지만 Park 과Jeong ${ }^{37}$ 은 플랭크 도중 외부 저항이 몸통근의 근두께에 효과 적으로 작용하였다고 하여 본 연구 결과를 지지하고 있다. 본 연구의 4 주 후의 적은 변화량은 2 주까지 호흡만 이용하였고 3 주 차부터 팔 의 45 도 벌림 운동을 추가하여 5 주 후부터 90 도 벌림 운동을 적용하 여 자극 강도 차이와 대상자의 남.여 선정 비율 차이 때문으로 생각 된다. harms 등 34 은 몸통 강화 운동 프로그램의 신체 구성 변화 성공 률이 성별 구성에 따라 달라진다고 하며 여성은 호흡기계의 구조적 차이와 호르몬 차이로 인해 남성보다 운동에 대한 반응 효과가 떨어 진다고 하여 ${ }^{35}$ 본 연구에서 구성한 PERA의 15 명 중 9 명의 여성의 참 가자로 인해 차이가 없었던 것으로 생각된다. PERA의 남성 6명만을 이용하여 시기별 변화를 살펴본 결과 배바깥빗근은 4 주 후에 0.28 $\mathrm{mm}, 8$ 주 후에 $0.97 \mathrm{~mm}$ 증가하였고, 배속빗근은 4주 후에 $0.66 \mathrm{~mm}, 8$ 주 후에 $1.90 \mathrm{~mm}$ 의 증가를 했으며, 배가로근은 4 주 후에 $0.53 \mathrm{~mm}, 8$ 주 후에 $1.30 \mathrm{~mm}$ 의 증가를 해 남성을 대상으로 한 결과가 전체를 대상 으로 한 결과보다 좋은 결과를 보여 선행연구를 지지하고 있다.

본 연구는 표본집단의 크기가 작았고 건강한 20대 성인을 대상으 로 하여 급성과 만성 질환 환자나 노인과 같은 특수성을 가진 집단에 는 일반화하기에는 어렵다. 하지만 실험을 통해 발생한 변화량은 긍 정적으로 생각되며 향후 연구에서는 근 빼대계 질환이나 특수성을 가진 대상자들과 연령층의 다변화로 심도 있는 연구가 필요해 보이 며 본 연구에서 확인하지 못한 호흡과 팔과 다리의 움직임을 좀 더 세 분화한 연구와 도구를 이용한 다변화된 연구가 필요해 보인다. 결론 으로 본 연구는 건강한 성인을 대상으로 호흡과 팔의 움직임을 병행 한 플랭크 운동은 복부 근육 중 배속빗근과 배가로근의 두께 증가가 발생하여 임상에서 재활 치료로써 활용 가치와 기초 자료로 활용 가 능성을 기대해본다. 


\section{ACKNOWLEDGEMENTS}

이 논문은 2018년도 남부대학교 학술연구비의 지원을 받아 연구되었음.

\section{REFERENCES}

1. Lee HK, Cho YH, Lee JC. The effect of improve the waist flexibility, the waist muscular strength and the waist balance which grafted in william \& mckenzie exercise with swiss ball. J Korean Soc Phys Med. 2013; 8(4):479-87.

2. Reeves NP, Cholewicki J. Modeling the human lumbar spine for assessing spinal loads, stability, and risk of injury. Crit Rev Biomed Eng. 2003;31(1-2):73-139.

3. Kang JI, Choi HH. Effects of 3d stabilization exercise on the muscle activity and static balance of patients with lumbar instability. J Kor Phys Ther. 2017;29(4):181-6.

4. Lim JH. Effects of flexible pole training combined with lumbar stabilization on trunk muscles activation in healthy adults. J Kor Phys Ther. 2018;30(1):1-7.

5. Kong YS, Hwang YT. Comparison of the activity and proprioception of trunk muscles according to different types of bridge exercises in subjects with and without chronic low back pain. J Kor Phys Ther. 2015;27(6): 400-6.

6. Bak JW, Shim SY, Cho MK et al. The effect of plank exercises with hip abduction using sling on trunk muscle activation in healthy adults. J Kor Phys Ther. 2017;29(3):128-34.

7. Snarr RL, Esco MR. Electromyographical comparison of plank variations performed with and without instability devices. J Strength Cond Res. 2014;28(11):3298-305.

8. Ekstrom RA, Donatelli RA, Carp KC. Electromyographic analysis of core trunk, hip, and thigh muscles during 9 rehabilitation exercises. J Orthop Sports Phys Ther. 2007;37(12):754-62.

9. Fitts PM, Posner MI. Human performance. Belmont, Brookes. 1967.

10. Mehling WE. The experience of breath as a therapeutic interventionpsychosomatic forms of breath therapy. A descriptive study about the actual situation of breath therapy in germany, its relation to medicine, and its application in patients with back pain. Forsch Komplementarmed Klass Naturheilkd. 2001;8(6):359-67.

11. Lee DK, Kang MH, Kim JW et al. Effects of non-paretic arm exercises using a tubing band on abdominal muscle activity in stroke patients NeuroRehabilitation. 2013;33(4):605-10.

12. Wang HY, Chen CC, Hsiao SF. Relationships between respiratory muscle strength and daily living function in children with cerebral palsy. Res Dev Disabil. 2012;33(4):1176-82.

13. Chang WN, Min WK, Lee HK. The effects of assisted respiratory training using functional electrical stimulation on respiratory function in patients with tetraplegia. J Korean Soc Neur Ther. 2016;20(2):39-46.

14. Nam HC, Jo YJ, Kang BJ et al. A study on the effect of trunk stabilization program on body balance, lung capacity, muscular activity of healthy adults. Journal of The Korean Society of Integrative Medicine. 2015; 3(4):43-51.

15. Ishida $\mathrm{H}$, Watanabe $\mathrm{S}$. Influence of inward pressure of the transducer on lateral abdominal muscle thickness during ultrasound imaging. J Orthop Sports Phys Ther. 2012;42(9):815-8.

16. Lee TH. The effects on back strength by the breath training. Journal of Sport and Leisure Studies. 2008;34(2):1247-55.

17. Kim ST. The effects of pilates breathing trainings on trunk muscle activation in healthy female subjects. Cheongju University. Dissertation of Master's Degree. 2017.

18. García-Vaquero MP, Moreside JM, Brontons-G.E et al. Trunk muscle activation during stabilization exercises with single and double leg support. J Electromyogr Kinesiol. 2012;22(3):398-406.

19. Mok NW, Yeung EW, Cho JC et al. Core muscle activity during suspension exercises. J Sci Med Sport. 2015;18(2):189-94.

20. Yang SR, Kim YM, Park SJ et al. Efficacy of lumbar segmental stabilization exercises and breathing exercises on segmental stabilization in lumbar instability patients. J Kor Phys Ther. 2017;29(5):234-40.

21. Hodges PW, Gandevia SC. Changes in intra-abdominal pressure during postural and respiratory activation of the human diaphragm. J Appl Physiol. 2000;89(3):967-76.

22. Jung DY, Koh EK, Kwon OY et al. Effect of medial arch support on displacement of the myotendinous junction of the gastrocnemius during standing wall stretching. J Orthop Sports Phys Ther. 2009;39(12):86774 .

23. Janssens L, McConnell AK, Pijnenburg M et al. Inspiratory muscle training affects proprioceptive use and low back pain. Med Sci Sports Exerc. 2015;47(1):12-9.

24. Hodges PW, Richardson CA. Transversus abdominis and the superficial abdominal muscles are controlled independently in a postural task. Neuroscience. 1999;265(2):91-4.

25. Lee JA, Kim SY. Reliability of ultrasonography for the longus colli in asymptomatic subjects. J Kor Phys Ther. 2011;23(4):59-66.

26. Rankin G, Stokes M, Newham D. Size and shape of the posterior neck muscles measured by ultrasound imaging: normal values in males and females of different ages. Man Ther. 2005;10(2):108-15.

27. Sung N. Analysis and experiment of repetitive measurement. Seoul. Free Academy. 1997:113.

28. Ishida H, Hirose R, Watanabe S. Comparison of changes in the contraction of the lateral abdominal muscles between the abdominal drawingin maneuver and breathe held at the maximum expiratory level. Man Ther. 2012;17(5):427-31.

29. Park DJ. Altered respiratory pattern of individuals with lbp and effects of abdominal exhalation maneuver. Daehan University. Dissertation of Doctorate Degree. 2013.

30. Cortell-Tormo JM, García-Jaén M, Chulvi-Medrano I et al. Influence of scapular position on the core musculature activation in the prone plank exercise. J Strength Cond Res. 2017;31(8):2255-62.

31. Imai A, Kaneoka K, Okubo Y et al. Trunk muscle activity during lumbar stabilization exercises on both a stable and unstable surface. J Orthop Sports Phys Ther. 2010;40(6):369-75.

32. Kisner C, Colby LA, Borstad J. Therapeutic exercise: Foundations and techniques. Fa Davis, 2017: Pages

33. Calatayud J, Casaña J, Martín F et al. Trunk muscle activity during different variations of the supine plank exercise. Musculoskelet Sci Pract. 2017;28:54-8.

34. Harms CA, Babcock MA, McClaran SR et al. Respiratory muscle work 
compromises leg blood flow during maximal exercise. J Appl Physiol. 1997;82(5):1573-83.

35. Harms CA, Rosenkranz S. Sex differences in pulmonary function during exercise. Med Sci Sports Exerc. 2008;40(4):664-8.

36. Mullington CJ, Klungarvuth L, Catley M et al. Trunk muscle responses following unpredictable loading of an abducted arm. Gait posture. 2009;30(2):181-6.

37. Park JC, Jeong JG. Effects of Plank Exercises with Resistance of One-Sided Hip Adduction on the Abdominal Muscle Thickness. J Kor Phys Ther. 2019;31(2):82-7. 